\title{
Comprehensive paleomagnetic study of a succession of Holocene olivine-basalt flow: Xitle Volcano (Mexico) revisited
}

\author{
Luis M. Alva-Valdivia \\ Laboratorio de Paleomagnetismo y Geofisica Nuclear, Instituto de Geofisica, Universidad Nacional Autónoma de México, \\ Del. Coyoacan 04510 Mexico City, Mexico
}

(Received October 18, 2004; Revised June 9, 2005; Accepted June 28, 2005)

\begin{abstract}
A detailed paleomagnetic study of a young Late Holocene olivine-basalt flow from the Xitle volcano in the southern Basin of Mexico was completed to evaluate the consistency and reliability of the record derived from fresh well-preserved and exposed lava flows. One-hundred oriented standard paleomagnetic cores corresponding to 10 different lava effusion episodes were collected from unit-flow V. Thermomagnetic analyses show that bulk magnetic properties and remanence is carried in most cases by Ti-poor titanomagnetite, presumably resulting from oxy-exsolution processes during the initial flow cooling. Unblocking temperature and coercivity suggests pseudo-single domain magnetic grains for these (titano)magnetites. Thermal and alternating field demagnetizations show well-defined univectorial magnetizations. Most sites present a mean direction with small angular dispersion around the dipolar direction for central Mexico. The overall mean direction $\left(N=10\right.$, Dec $=1.1^{\circ}$, Inc $=34.1^{\circ}, k=531$ and $\alpha_{95}=2.1^{\circ}$ ) is characterized by small angular dispersion and inclination close to the dipolar value for the locality. Anisotropy of magnetic susceptibility lineation agrees with the geologically-inferred flow direction. Various samples from the 10 lava flows were selected for Thellier paleointensity experiments because of their stable remanent magnetization and relatively low within-site dispersion. According to reliability parameters, the obtained paleointensities are of reasonably good quality. Nine mean paleointensities range between 48.6 and $73.9 \mu \mathrm{T}$. The overall mean paleointensity of 59.9-7.7 $\mu \mathrm{T}$ is higher than the present-day field of $43 \mu \mathrm{T}$, consistent with the global data for this time-period. Most samples presented alteration during the cooling rate test, and no correction was made to these samples. Those samples on which cooling-rate correction was applied give a flow mean lower than the raw paleointensity data, as was expected.
\end{abstract}

Key words: Paleomagnetism, lava-flows, Xitle volcano, Mexico.

\section{Introduction}

The Xitle volcano is probably the youngest among more than 200 scoria and cinder cones in the Quaternary Chichinautzin monogenetic volcanic field of the southern Basin of Mexico (Herrero-Bervera et al., 1986; Urrutia-Fucugauchi and Martin del Pozzo, 1993). Volcanic eruption began with basaltic tephra emission, followed by several basaltic lava flows, which flowed downslope in a northerly direction, covering an area of c. $80 \mathrm{~km}^{2}$ (Fig. 1) (Badilla-Cruz, 1977).

The age of the Xitle eruption has remained a subject of considerable interest. Radiocarbon dating has been applied since the initial development of the method (Arnold and Libby, 1951). The bulk of the samples, with good stratigraphic control, cluster around an age of c. 2000 years BP. A charcoal sample from the base of the section studied in this work has given a date of 1960-65 years BP. A younger age for the Xitle eruption of around 1670 years BP has also been recently proposed (Gonzalez et al., 2000; Siebe, 2000).

Duration of the Xitle eruption has not been determined; it can be similar to the historic eruptions of nearby vol-

Copyright (C) The Society of Geomagnetism and Earth, Planetary and Space Sciences (SGEPSS); The Seismological Society of Japan; The Volcanological Society of Japan; The Geodetic Society of Japan; The Japanese Society for Planetary Sciences; TERRAPUB. canoes in the Trans Mexican Volcanic Belt (TMVB), of the order of a decade or so (e.g. the 1943-1953 Paricutín: Luhr and Simkin, 1993; the 1759-1774 Jorullo eruptions: Bullard, 1976). Delgado et al. (1998) constructed a geologic map and stratigraphy for this volcano in which they distinguished up to seven major lava flow units (Fig. 1). In this work, I report on the study of the Ciudad Universitaria Basaltic Lava Member (BCU, Flow V; Delgado et al., 1998), which is formed by several minor flow units of olivine basalt. It represents the most extensive unit with the greatest extent and thickness. This suggests that BCU represents the convulsive phase of the eruption and had the lowest viscosity and largest effusion rate. These lavas show the best-preserved pahoehoe structures. A sequence of 10 lava flows was identified at an old quarry with a total average thickness of c. $35 \mathrm{~m}$ (Fig. 2). This flow surrounded and covered one of the earlier pyramids and settlements in the region (Cuicuilco archeological site). Walker (1991) performed detailed observations of vesicles, structures, flow lobes elongation, and terrain slope in order to infer the (geologically) overall flow direction (Fig. 1).

The purpose of this study is to analyze, from the paleomagnetic point of view, a sequence of 10 lava flows that belong to the Basaltic Lava Member (BCU, Flow V) present in this section located at the far-end of the Xitle lava field (Fig. 1). 


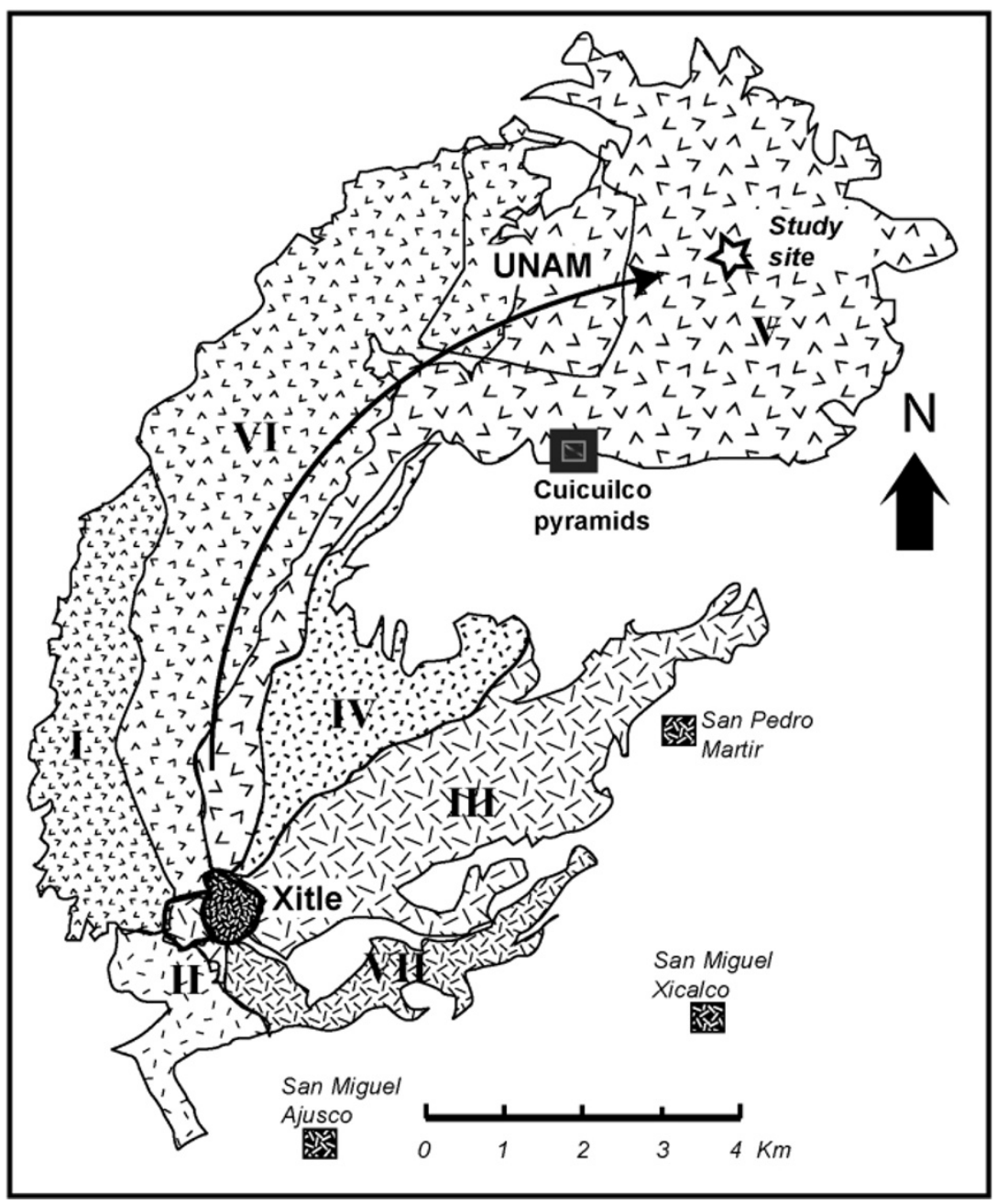

Fig. 1. Lava flow units identified by Delgado et al. (1998) and location of paleomagnetic sampling site (star). The large arrow indicates the geologically-inferred flow direction. UNAM is the Universidad Nacional Autónoma de México, Ciudad Universitaria campus.

Table 1. Paleodirectional results from Xitle olivine-basalt rocks: $N$ : Number of treated samples, $n$ : number of samples used for calculation, Dec: Declination, Inc: Inclination, $k$ and $\alpha_{95}$ : Precision parameter and radius of confidence cone.

\begin{tabular}{ccccccc}
\hline Site & Samples & $\mathrm{N} / \mathrm{n}$ & $\mathrm{Dec}$ & $\mathrm{Inc}$ & $\mathrm{K}$ & $\alpha_{95}$ \\
\hline flow 1 & 99U001-99U010 & $(10 / 9)$ & 3.8 & 31.7 & 87 & 5.6 \\
flow 2 & 99U011-99U020 & $(10 / 8)$ & 0.2 & 34.7 & 351 & 3.0 \\
flow 3 & 99U021-99U030 & $(10 / 10)$ & 2.0 & 33.5 & 131 & 4.2 \\
flow 4 & 99U031-99U040 & $(10 / 10)$ & 2.7 & 31.7 & 156 & 3.9 \\
flow 5 & 99U041-99U050 & $(10 / 8)$ & 2.9 & 34.7 & 72 & 6.6 \\
flow 6 & 99U051-99U061 & $(11 / 9)$ & 356.2 & 30.4 & 309 & 2.9 \\
flow 7 & 99U088-99U097 & $(10 / 9)$ & 5.1 & 35.9 & 280 & 3.1 \\
flow 8 & 99U098-99U108 & $(11 / 8)$ & 359.1 & 32.8 & 57 & 7.4 \\
flow 9 & 99U109-99U118 & $(10 / 7)$ & 356.7 & 37.8 & 117 & 5.6 \\
flow 10 & 99U119-99U126 & $(8 / 5)$ & 2.6 & 37.5 & 393 & 3.9 \\
Mean & & & 1.1 & 34.1 & 530.5 & 2.1 \\
\hline
\end{tabular}

\section{Paleomagnetic Study}

\subsection{Sampling and laboratory procedures}

In the quarry, seven flow units can be observed, with thicknesses varying from 2 to $8 \mathrm{~m}$ (Fig. 2). Lava flows 3 and 4 were sampled $14 \mathrm{~m}$ to the left of the picture which are interbedded between 2 and 5 lava flows. Three other flows (flows 8, 9 and 10) are out of the quarry overlying the others, of 1.5-3 m thickness. Samples were collected mainly from around $1 \mathrm{~m}$ above the basal part of each flow (mostly free of vesicles). This place is currently the training camp of the PUMAS Club (UNAM soccer team).

Lava flows for the 10 effusive eruptive events were sam- 


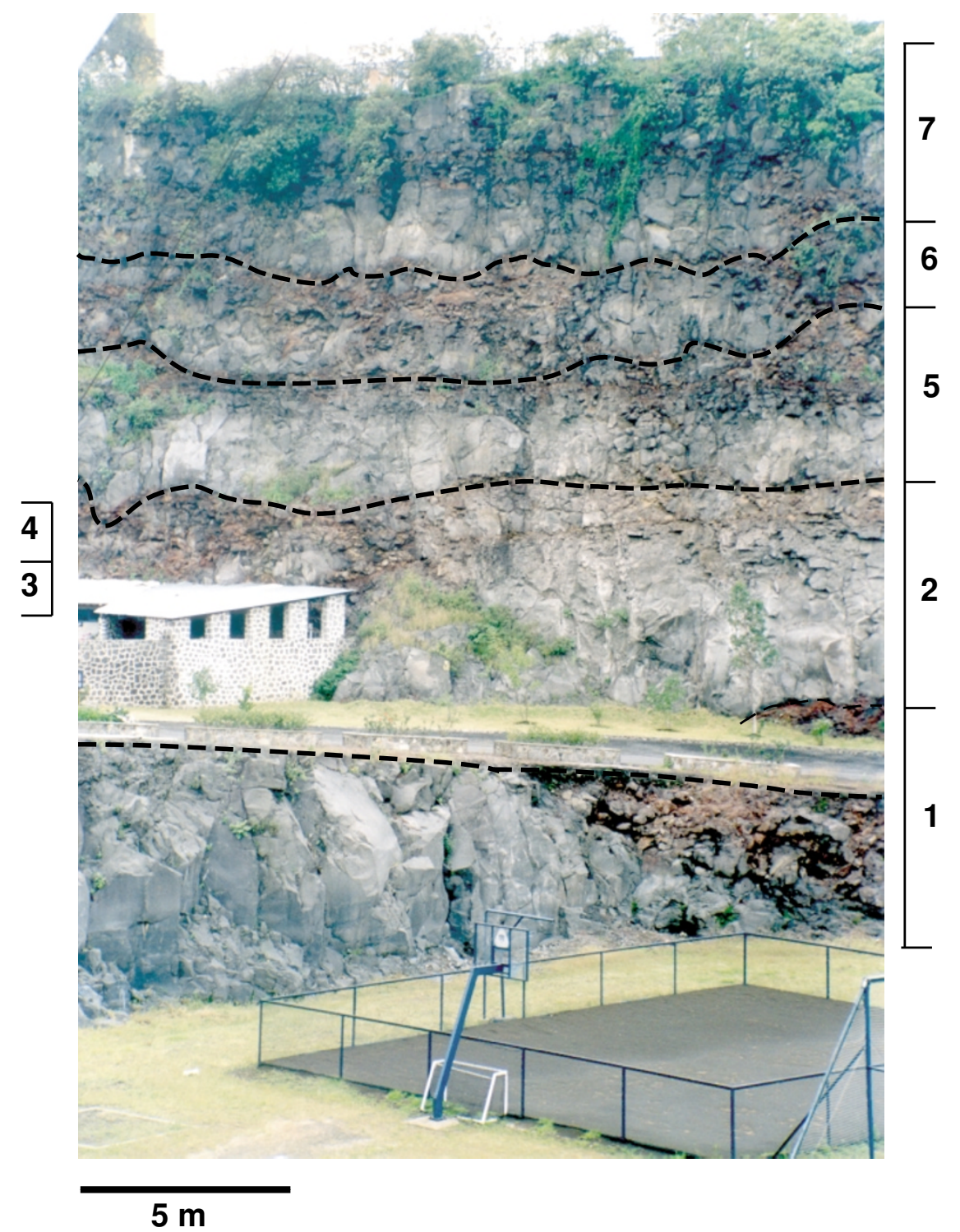

Fig. 2. Photograph showing the lava flows at the sampling site (see flow numbers at both sides).

pled for the paleomagnetic study. One hundred samples were drilled in the field with a portable gasoline-powered drill and oriented with both solar and magnetic compasses, excluding some sites in which local conditions (outcrop characteristics and weather) banned the use of the sun compass. Between 8 and 11 samples were collected at each site (Table 1).

The natural remanent magnetization (NRM) was measured with a JR5 spinner magnetometer. The anisotropy of magnetic susceptibility was measured using a KLY-2 bridge (AGICO, Brno). The stability and vectorial composition of NRM of every sample were investigated by a step-wise alternating field (AF) and thermal demagnetization. AF demagnetization was carried out in $8-12$ steps up to 100 mT using a Schonstedt AF demagnetizer in the three-axes stationary mode. Stepwise thermal demagnetization up to $500-550^{\circ} \mathrm{C}$ using a non-inductive Schonstedt furnace was carried out on one sample per flow.

Samples are characterized by simple univectorial (Fig. 3) or, rarely, two-component plots. The characteristic direc- tion (ChNRM) for each sample was calculated from the vector plots and corresponds to the vector component going through the origin (samples for which the vector plots did not pass through the origin were not used for the calculation of site means). Site-mean directions were calculated by vector addition giving unit weight to sample directions. Fisherian statistics was used to estimate dispersion parameters. The overall-mean direction was calculated giving unit weight to site-mean directions. Site-mean directions and overall-mean direction, and associated statistical parameters, are summarized in Table 1 and graphically illustrated in Fig. 4.

\subsection{Microscopy}

We follow the oxidation and texture state classification of Haggerty (1976) and Buddington and Lindsley (1964), respectively. Oxidation of classifications, C1 to C7 for titanomagnetite, and R1 to R7 for ilmenite (prefix C distinguished primary cubic phases from primary rombohedral phases, $\mathrm{R})$, are applied to studies of rock magnetism. Titanomagnetite can be oxidized by two mechanisms: (1) oxidation 


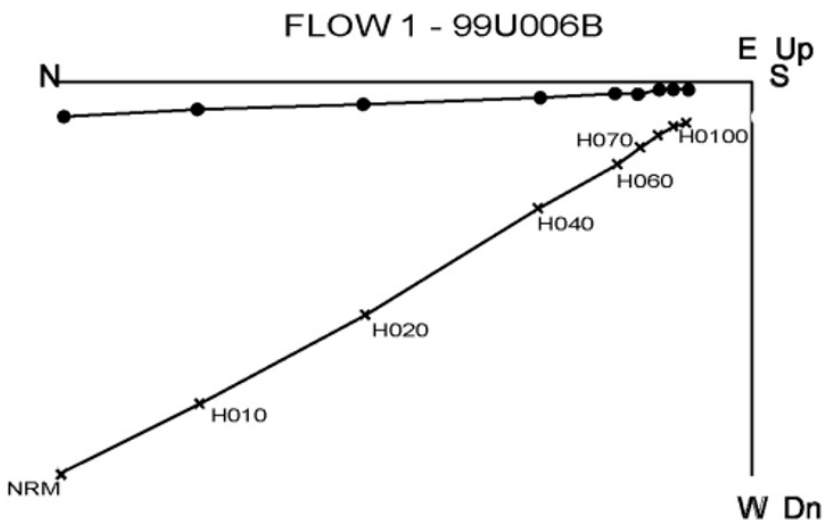

FLOW 4 - 99U033A
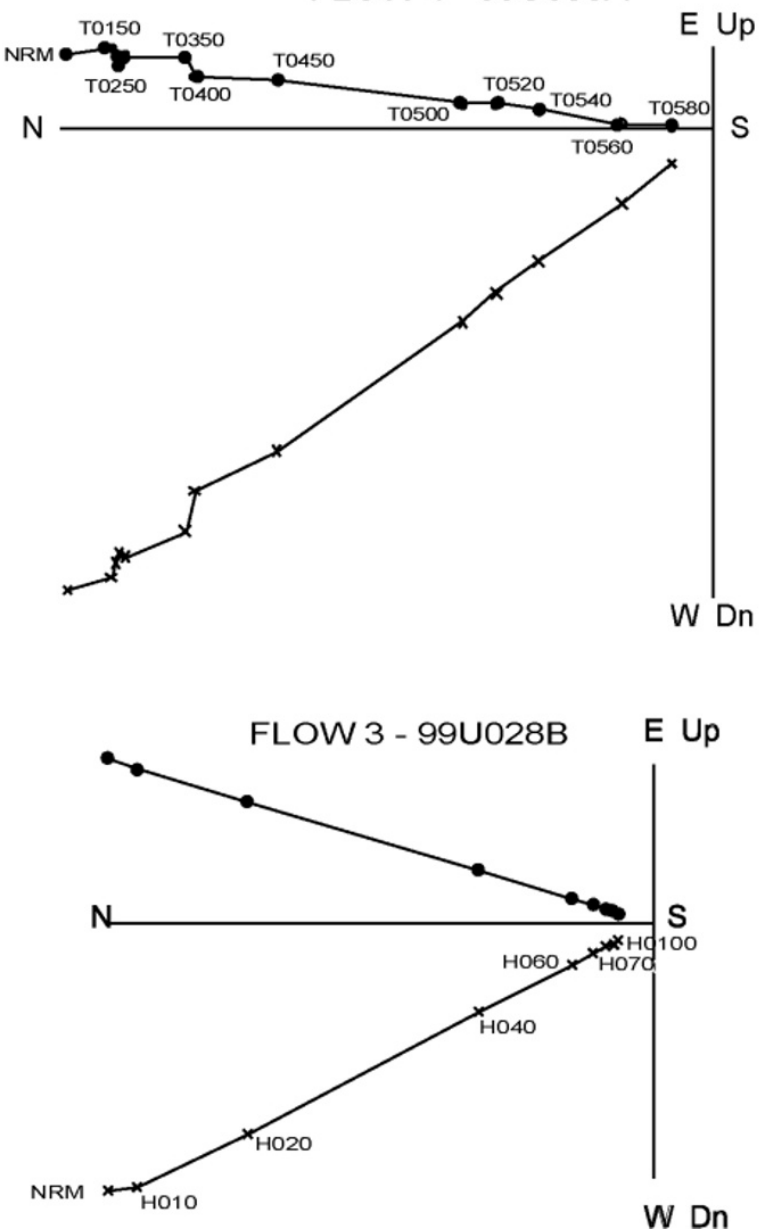

Fig. 3. Orthogonal vector plots of stepwise alternating field and thermal demagnetizations (geographic coordinates). The numbers refer either to the temperatures in ${ }^{\circ} \mathrm{C}$ or to peak alternating fields in $\mathrm{mT}$. - - projections into the horizontal plane, $x$-projections into the vertical plane.

at low pressure and below $600^{\circ} \mathrm{C}$ to yield a cation-deficient spinel of the metastable titanomaghemite series, which in some cases may convert to members of the titanohematite series, and (2) oxidation at low to moderate pressure and above $600^{\circ} \mathrm{C}$ with the direct formation of titanohematites. On the other hand, ilmenite intergrowths in titanomagnetite are divided into trellis, sandwich and composite textures. Trellis lamellae result from oxidation-exsolution, whereas

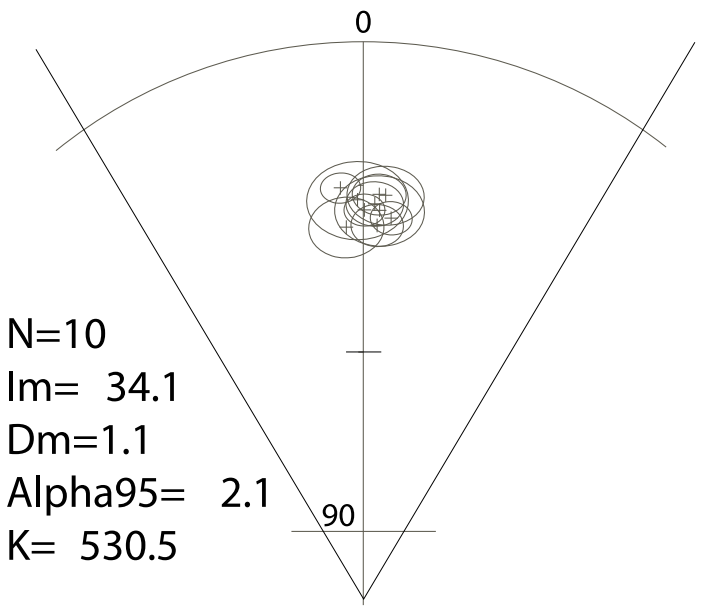

Fig. 4. Stereographic plot (zoom in) of site-mean directions for the Xitle lavas (data and Fisherian statistical parameters are given in Table 1).

sandwich and composite ilmenites can be a product of either oxidation or primary crystallization. The representative microphotographs shown in Fig. 5 were taken with a $50 \times$ and $125 \times$ oil immersion objective and a high-resolution digital camera.

In general, we agree with the opaque mineral description of samples from the lowermost part of the Xitle lava flows by Böhnel et al. (1997), pointing to the presence of small euhedral titanomagnetites and ilmenites, in disseminated form or with skeletal textures. The state of oxidation of titanomagnetites mineral series is $\mathrm{C} 2$, for skeletal grains, but some subhedral grains with C3-C5 are also present. Titanomagnetite grain sizes vary from about $1-25 \mu \mathrm{m}$. As well, some samples belong to titanohematites series of sizes up to $80 \mu \mathrm{m}$ and R2-R3 oxidation states (Haggerty, 1976).

Representative microphotographs and a concise description of opaque minerals supported by observations of polished sections under reflected light and oil immersion for selected representative samples is shown in Fig. 5, and described below. The importance of direct oxide mineral observations is significant because of their contribution to investigate the origin of magnetization.

Sample 99U023A shows pseudomorphous euhedral and anhedral crystals consisting of titanomagnetite altered to maghemite along its borders. This is a $\mathrm{C} 1-\mathrm{C} 2$ oxidation state (Haggerty, 1976). Another view of the same sample (99U023B) shows titanohematite pseudomorphous of skeletal texture, pseudobrookite lamellae and ilmenite relicts. Granular rutile is visible along the borders. This is an R2-R3 oxidation state.

Sample 99U047 shows tabular primary ilmenite partly hematized, and granular rutile homogeneously disseminated in the vitreous matrix (R1-R2 oxidation state).

Finally, sample 99U101 shows skeletal growth morphologies of titanohematites and intergrown pseudobrookite, indicative of a progressive trend towards euhedral morphology.

In summary, titanomagnetite seems to be the main magnetic carrier in the studied rocks. It is inhomogeneous with ilmenite intergrowths showing a light gray-brown color, sometimes fractured or with a brecciated texture. The gen- 


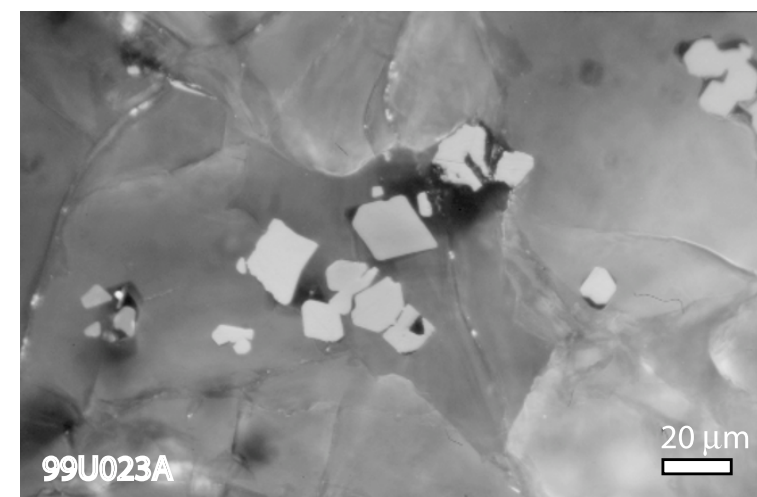

Flow 3

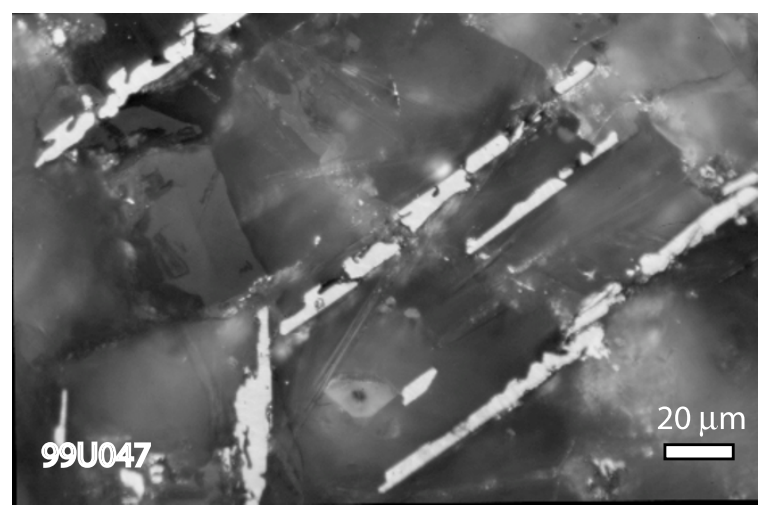

Flow 5

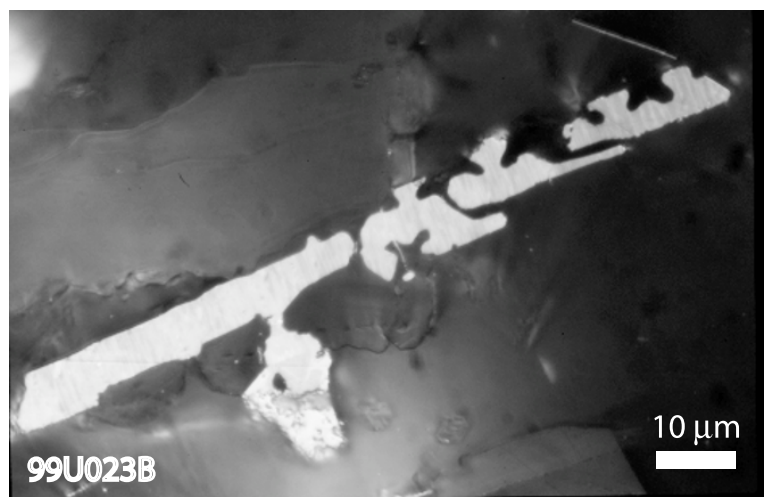

Flow 3

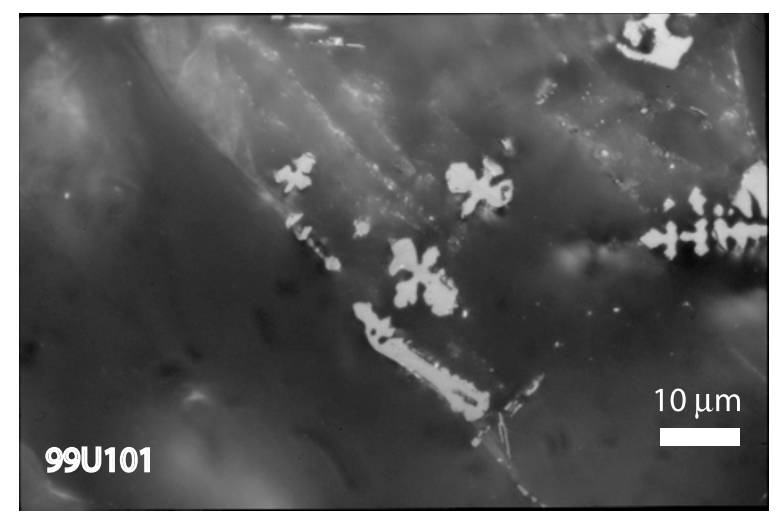

Flow 8

Fig. 5. Microphotographs representative of the opaque minerals from the lava flow V of Xitle volcano.

eral characteristics of magnetic mineralogy show deuteric oxidation of degree $\mathrm{C} 1$ to $\mathrm{C} 5$ and $\mathrm{R} 1$ to R3 (Haggerty, 1976) and possible low-to-medium grade hydrothermal alteration. These microscopic observations under microscope suggest that the natural remanent magnetization carried by these grains is a thermoremanent magnetization, because the described paragenesis typically develops at temperatures higher than $600^{\circ} \mathrm{C}$ (O'Reilly, 1984).

\section{Rock Magnetism}

\subsection{Susceptibility vs temperature measurements}

Low-field susceptibility measurements were carried out in air using a Highmoore susceptibility bridge equipped with a furnace in order to identify the magnetic minerals responsible for magnetization. Initial susceptibility was recorded between room temperature and $600^{\circ} \mathrm{C}(k-T$ curves). One sample from each site was heated at a rate of $20^{\circ} \mathrm{C} / \mathrm{min}$ and then cooled at the same rate. The Curie temperature determined by Grommé et al.'s (1969) method indicates, in all cases, the presence of Ti-poor titanomagnetites (Fig. 6). A few sites show evidence of two ferrimagnetic phases during heating (like sample 99U100). The cooling curves show only a single phase, with a Curie temperature close to that of magnetite. Irreversible $k-T$ curves can be explained by titanomaghemite, which converts to magnetite (Özdemir, 1987) during heating (samples 99U045 and 99U100).

\subsection{Hysteresis measurements}

Particular samples from each site were studied using the AGFM 'Micromag' apparatus in fields up to $1.2 \mathrm{~T}$, which provide hysteresis curves, direct field isothermal remanent magnetization (IRM) acquisition and back-field curves for micro samples. Magnetic carriers are likely Ti-poor titanomagnetites that present pseudo-single domain behavior. The coercivity of remanence $\left(H_{c r}\right)$ was determined by progressively applying increasing backfield after saturation. Three typical hysteresis plots are shown in Fig. 7. The curves are quite symmetrical in all cases. The saturation remanent magnetization $\left(J_{r s}\right)$, saturation magnetization $\left(J_{s}\right)$ and coercive force $\left(H_{c}\right)$ were calculated after correction for the paramagnetic contribution. IRM acquisition curves were very similar for all samples (Fig. 7 right side). Judging from the ratios of hysteresis parameters $\left(H_{c r} / H_{c}\right.$ ranges between 1.62 and 2.32 and $J_{r s} / J_{s}$ varies from 0.17 to 0.34 ), all samples fall in the pseudo-single domain (PSD) grain size region (Day et al., 1977; Fig. 8(a)), probably indicating a mixture of multidomain (MD) and a significant amount of single domain (SD) grains. Saturation is reached in moderate fields of 200-400 mT, which points to spinels as remanence carriers. Following Tauxe et al. (2002), we plot hysteresis parameters showing those that belong to the vortex remanent states' contribution to PSD hysteresis behavior, as suggested by Williams and Dunlop (1995) (Fig. 8(b)).

\subsection{Thellier paleointensity experiments}

Following the paleodirectional and rock-magnetic results, altogether 69 samples belonging to each of the 10 cooling units, yielding stable, one-component magnetization with blocking temperatures compatible to the nearmagnetite phase and with relatively high median destructive field (MDF) values, were selected for paleointensity (PI) ex- 

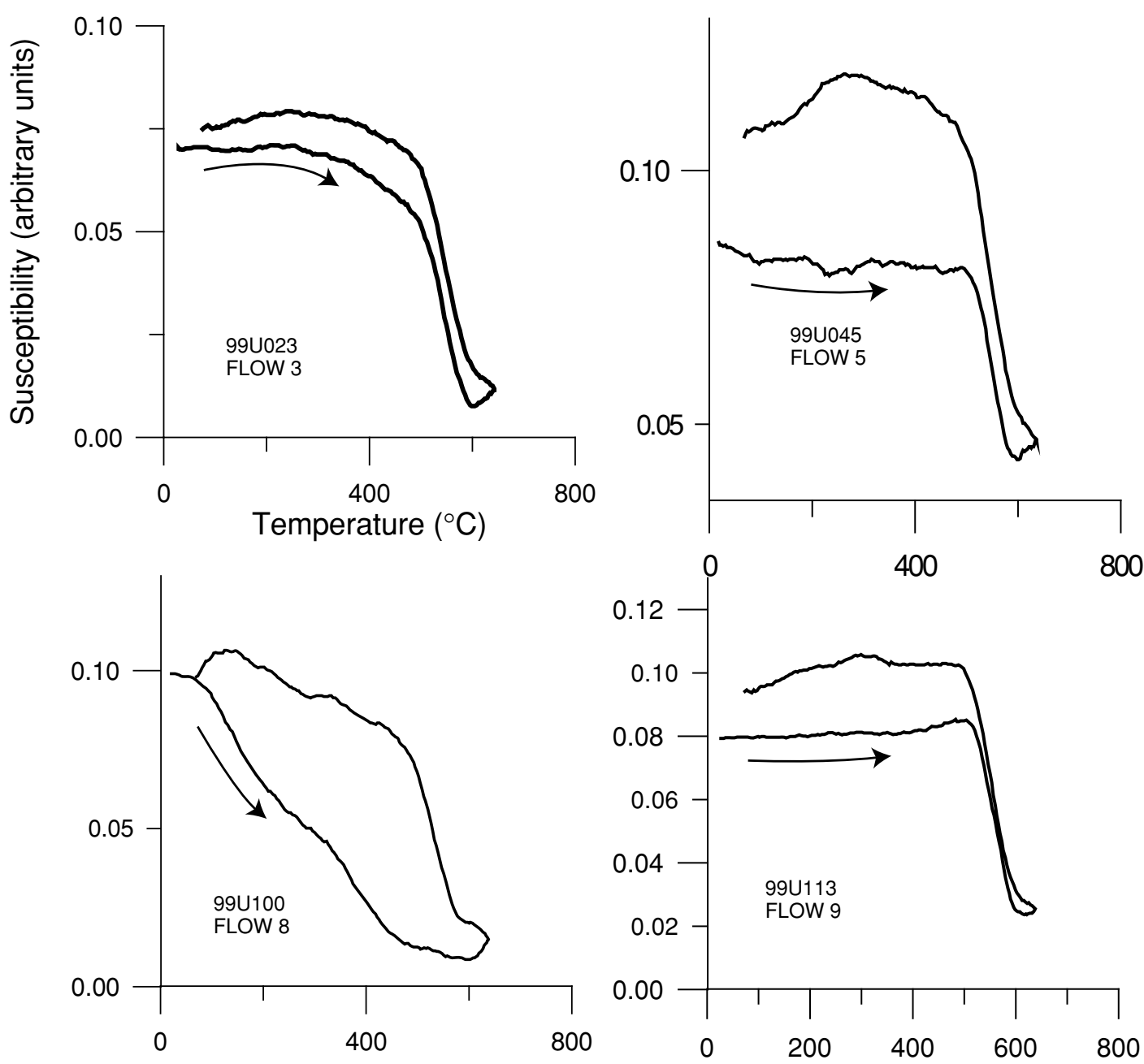

Fig. 6. Representative continuous susceptibility curves versus temperature (arrows indicate the heating branch).

periments.

PI measurements were completed using the Thellier method (Thellier and Thellier, 1959) in its modified form (Coe et al., 1978) combined with controlled heatings (socalled pTRM checks). Heating and cooling was done in air using a Magnetic Measurements thermal demagnetizer (MMTD80). The experiments were carried out in two steps. For the first set of 10 pilot samples (i.e. one sample per site), 11 temperature steps were distributed between room temperature and $540^{\circ} \mathrm{C}$ and the laboratory field set to $40 \mu \mathrm{T}$. For the second set of samples (59 in total) only eight temperature steps were applied since their unblocking temperature spectra were already well identified and the laboratory field set to $30 \mu \mathrm{T}$.

PI data are reported on the NRM-TRM plot of Fig. 9 and the results are given in Table 2. NRM-TRM plots with the TRM normalized by the maximum TRM, were used in order of clarity. We accepted only determinations that fulfill the following criteria: (1) determinations obtained from at least four NRM-TRM points corresponding to an NRM fraction larger than $1 / 3$ (Table 2), (2) quality factor (Coe et al., 1978) of five or more, and (3) positive 'pTRM' checks, i.e., the deviation of 'pTRM' checks were less than $15 \%$. Directions of NRM remaining at each step obtained from the PI experiments are reasonably linear and point to the origin (Fig. 9). No deviation of remaining directions NRM towards the direction of applied laboratory field was observed. Finally, 56 samples, coming from nine individual basaltic lava flows, yielded acceptable PI estimates. The flow-mean PI is 59.9 $\pm 7.7 \mu \mathrm{T}$, higher than the present-day field. For these samples, the NRM fraction $f$ used for determination ranged between 0.34 to 0.94 and the quality factor $q$ from 5.1 to 78.5. They constitute the 'hard core' of the PI data set and are represented in bold in Table 2.

Thellier PI experiments have yielded moderately dispersed PI values (Fig. 9) from the historically observed geomagnetic intensity. Although samples yielded technically high quality PI results, the obtained values are significantly different from the actual value of about $43 \mu \mathrm{T}$.

In order to investigate an alternative cause for the dispersion/scatter of the PI values obtained, the cooling rate (CR) dependence of TRM was investigated following a modified procedure to that described by Chauvin et al. (2000). Seven to 10 samples were used from all the 10 lava flows for the CR experiment.

TRM gained during the last step of the Thellier experiment $\left(550^{\circ} \mathrm{C}\right)$ was subsequently designated as TRM1. At the same temperature, a new TRM (TRM2) was given to all 

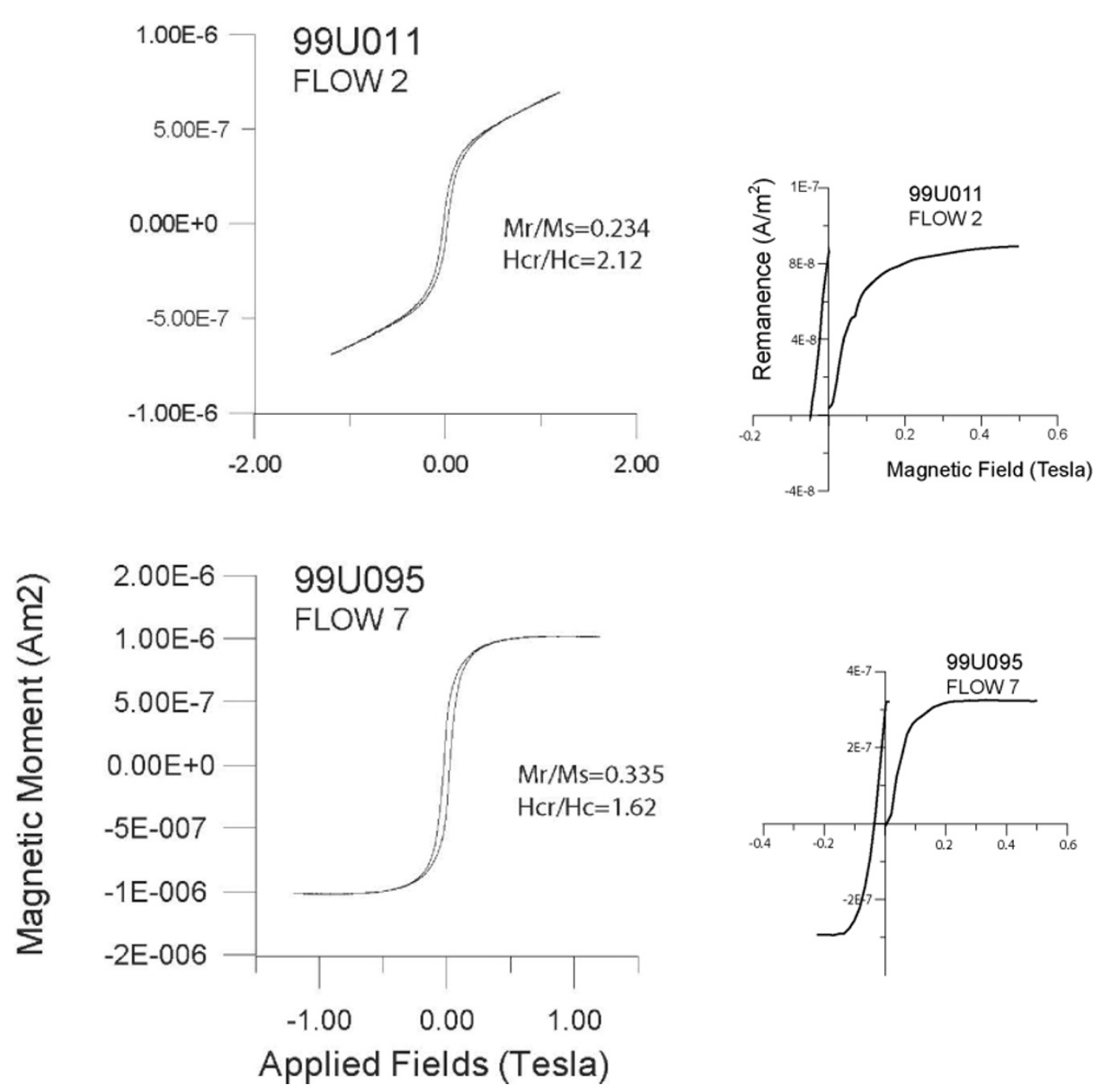

Fig. 7. Examples of hysteresis curves measured with a MicroMag system. SIRM of small rock chips (right side).

(a)

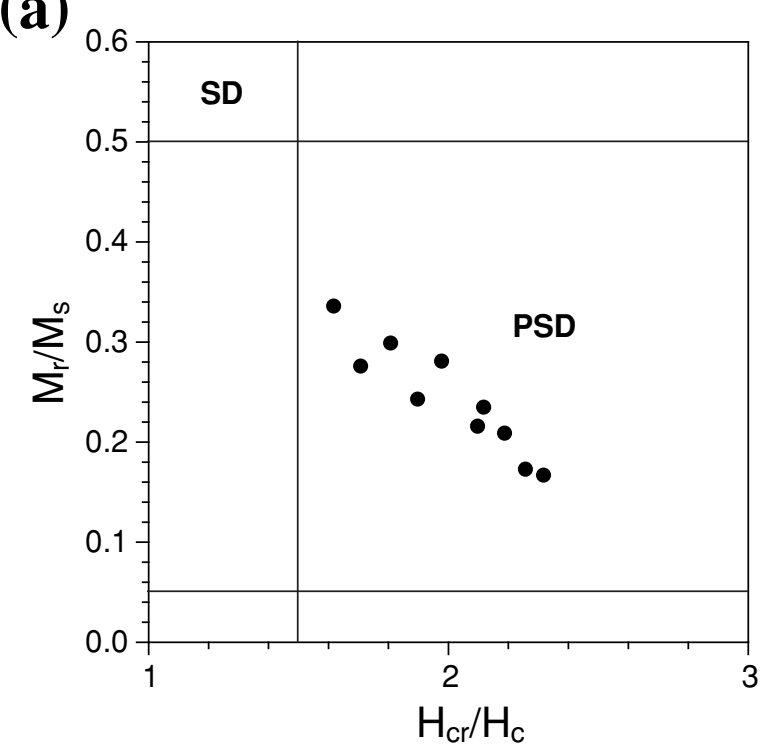

(b)

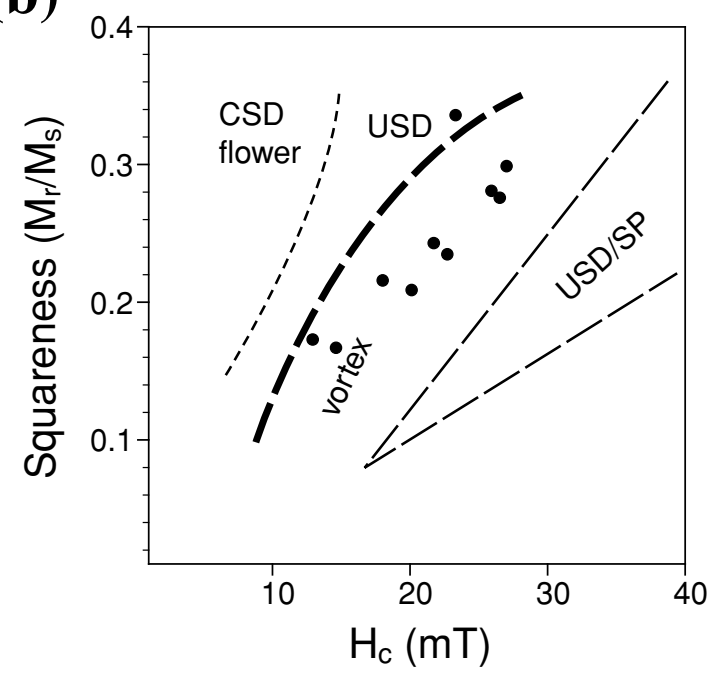

Fig. 8. (a) Magnetic hysteresis parameter ratios plotted in a Day diagram (Day et al., 1997); (b) Modified from Tauxe et al. (2002). 

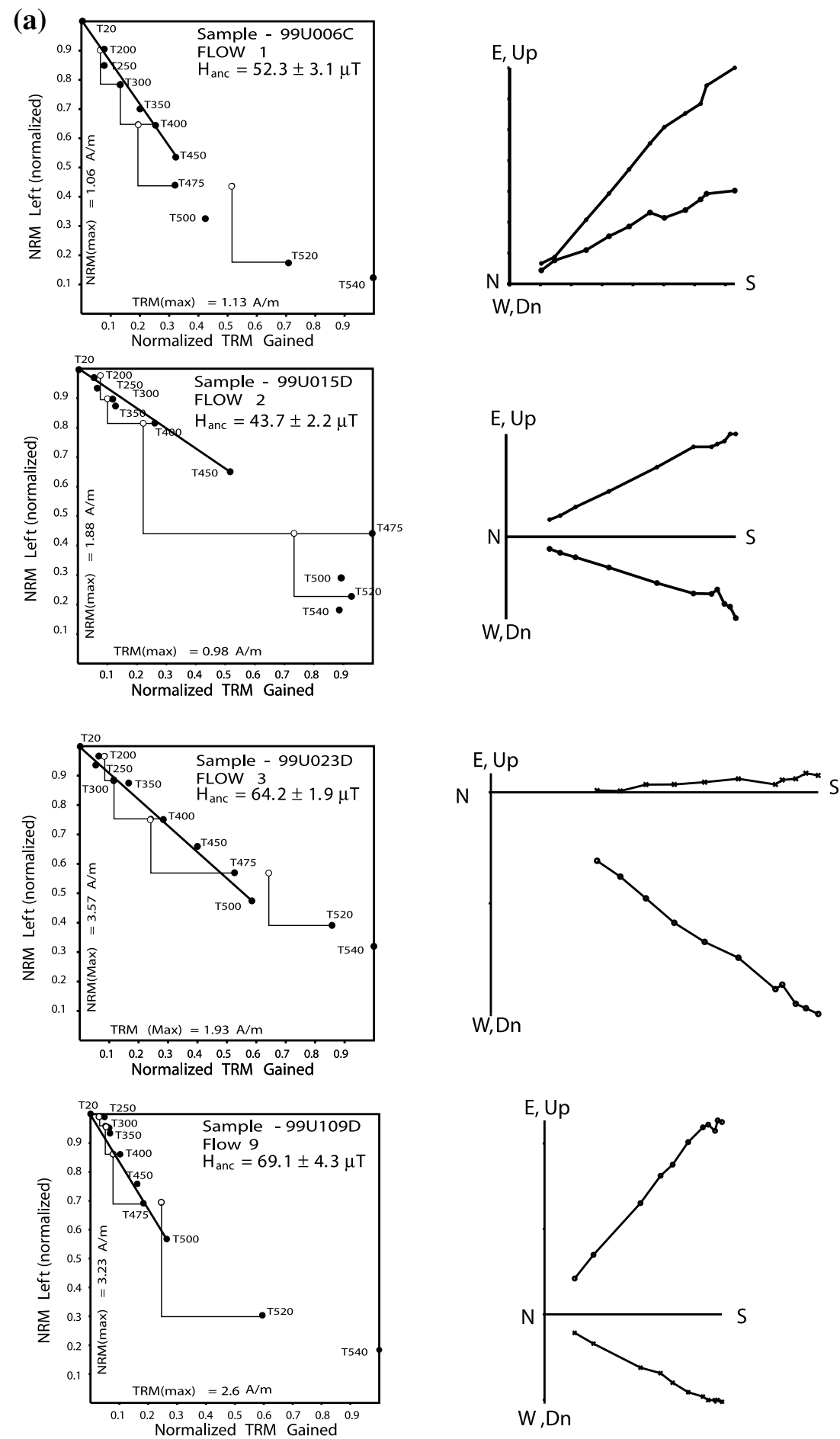

Fig. 9. Representative NRM-TRM plots in which, in order of clarity, the TRM is normalized by the maximum TRM. (A) First set (10 pilot samples, i.e. one sample per site) of samples with the laboratory field set to $40 \mu \mathrm{T}$. (B) Second set of samples (59 in total) with the laboratory field set to $30 \mu \mathrm{T}$.

samples using a long cooling time ( $\sim 12 \mathrm{hrs})$. Finally, a third TRM (TRM3) was created using the same cooling time (of about $45 \mathrm{~min}$ ) as that used to create TRM1. The effect of cooling rate upon TRM intensity was estimated by calculating the percentage variation $\left(R_{12}\right)$ between the intensity acquired during short and a long cooling times (TRM1 and TRM2), whereas variation in TRM acquisition capacity was estimated as a percentage variation $\left(R_{13}\right)$ between the intensity acquired during the same cooling time (TRM1 and TRM3). Cooling rate correction of raw PI values is based on the premise that $R_{13}$ should be lower than $15 \%$.

Unfortunately, most of the samples presented values of $R_{13}$ greater than $15 \%$, and no cooling rate correction was made to these samples. Those samples to which CR correction was applied gave a flow mean lower than the raw PI data, as was expected (Table 3 ).

\subsection{Anisotropy of magnetic susceptibility}

Essentially, the magnetic susceptibility of titanomagnetite grains depends on their shape. For irregular grains except single domain grains, it is maximum when mea- 

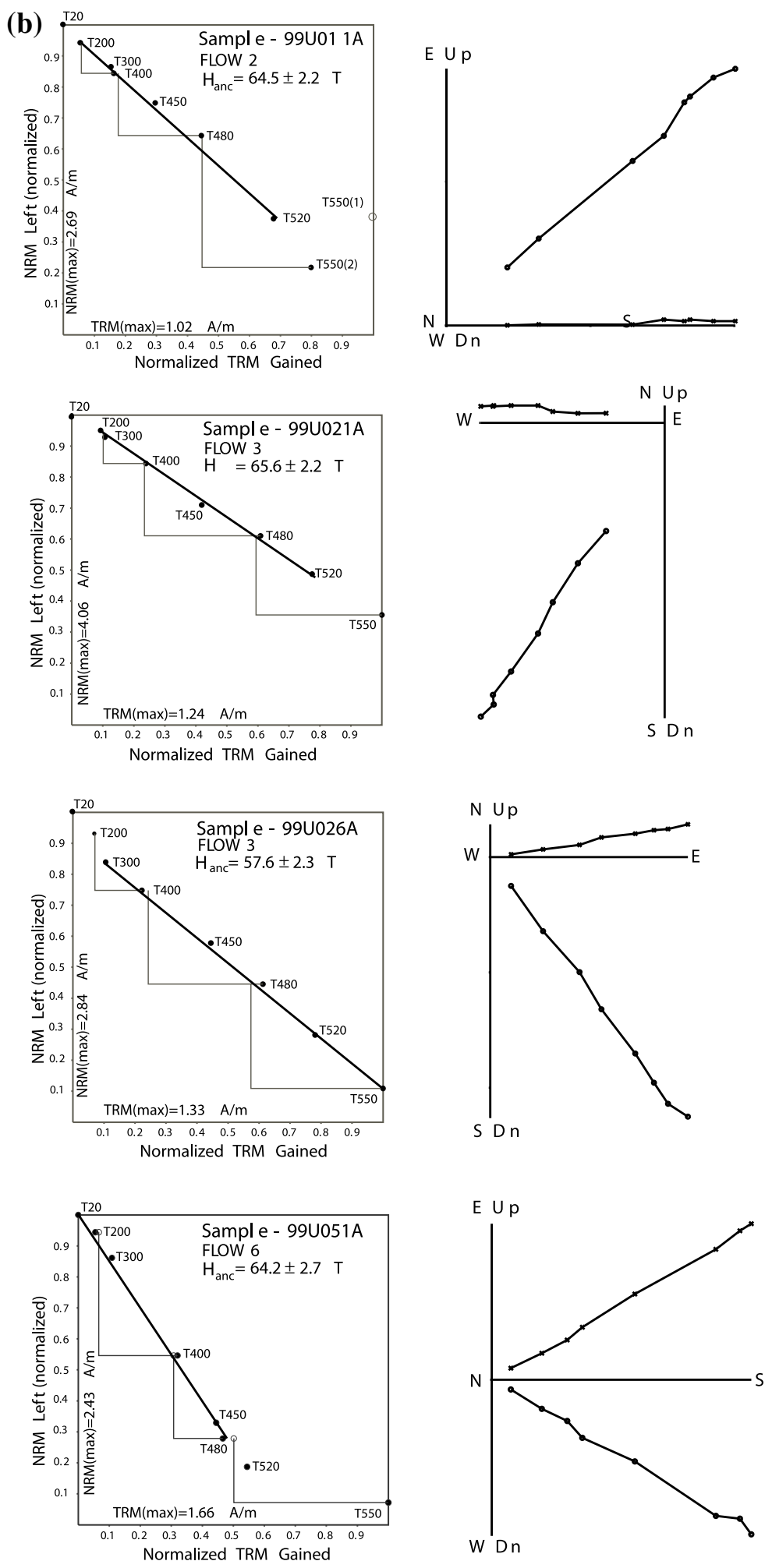

Fig. 9. (continued)

sured parallel to the longest axis and minimum when parallel to the shortest. The AMS of a titanomagnetite-bearing rock consequently indicates the spatial arrangement and preferred orientation of its titanomagnetite grains and is a powerful tool for investigating its fabric. For most lava flows that have been examined by the AMS technique, the anisotropy has been ascribed to the preferred shape alignment of magnetite or maghemite, both of which are cubic and typically occur in nearly equidimensional grains (e.g., Baer et al., 1997; Palmer and MacDonald, 1999). As a consequence, the degree of magnetic anisotropy due to the preferential alignment of long axes of these grains is small. For most sizes of these accessory grains of magnetite, the easy axis of a grain magnetization (its $K_{\max }$ axis) corresponds to the long dimension of the grain, whereas the direction of the least susceptibility (the $K_{\min }$ axis) corresponds to the short 
Table 2. Paleointensity results from the Xitle Volcano. $n$ is the number of NRM-TRM points used for paleointensity determination, $T_{\min }-T_{\max }$ is the temperature interval used, $f, g$ and $q$ are the fraction of extrapolated NRM used, the gap factor and quality factor (Coe et al., 1978), respectively. $F_{E} \pm \sigma\left(F_{E}\right)$ is the individual paleointensity with associated error. $F_{E} \pm$ s.d. is the site mean paleointensity with standard deviation. Accepted determinations are shown in bold (see also text). ${ }^{*}$ after the sample number indicate that they are pilot samples.

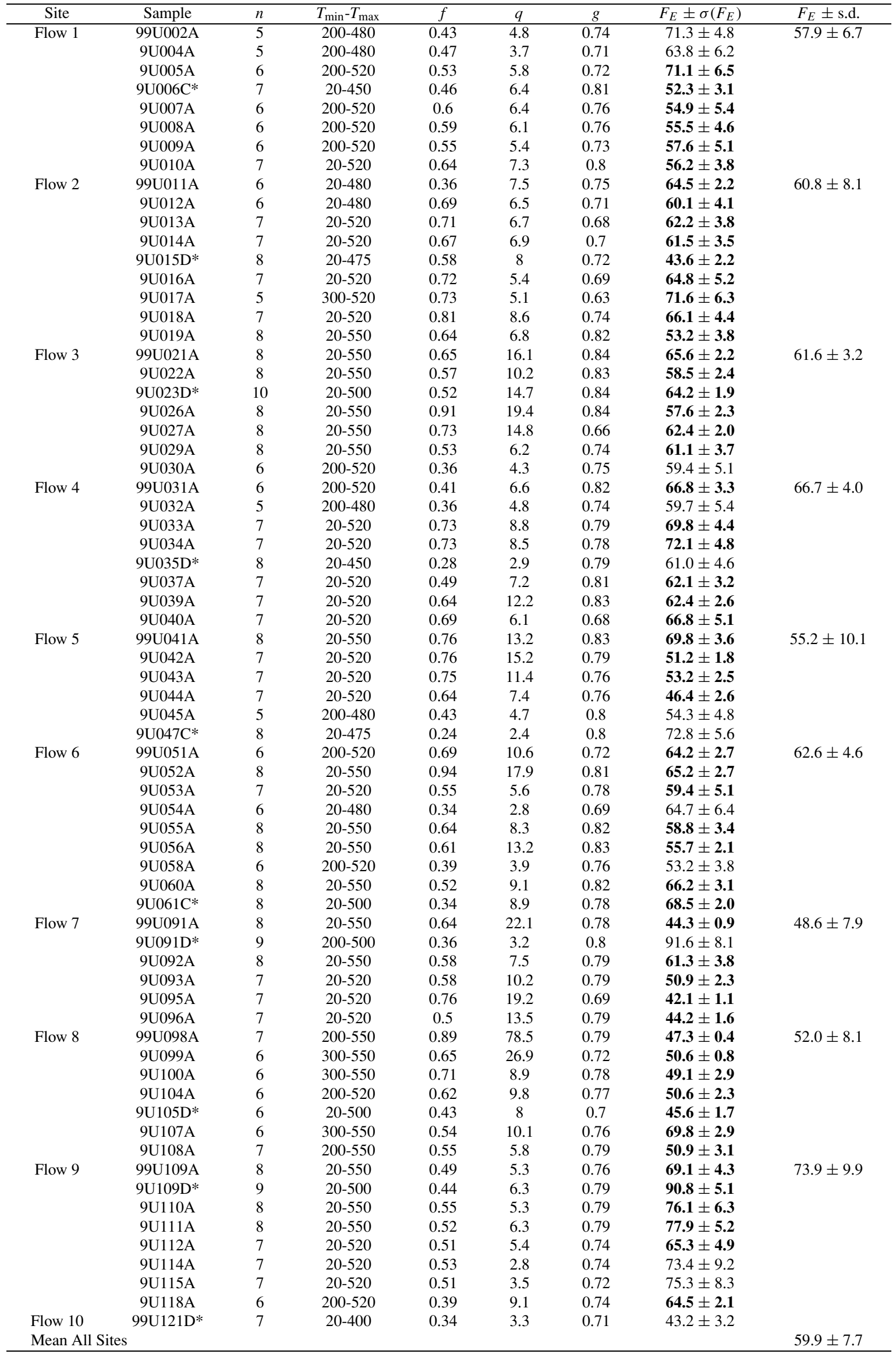


Table 3. Paleointensity results after cooling-rate (CR) correction. $R_{12}$ is defined as the percent difference between the TRM acquired with short CR vs TRM2 acquired with long CR. $R_{13}$ is defined as the percent variation in TRM acquisition capacity.

\begin{tabular}{|c|c|c|c|c|c|c|}
\hline Flow No. & Sample & $\begin{array}{c}\mathrm{PI}[\mu \mathrm{T}] \\
\text { Raw }\end{array}$ & $R_{12}$ & $R_{13}$ & $\begin{array}{l}\mathrm{PI}[\mu \mathrm{T}] \\
\text { CR-corr }\end{array}$ & \\
\hline 3 & 99U022A & 58.5 & 0.095 & 0.905 & 52.9 & \\
\hline 3 & 99U030A & 59.4 & 0.071 & 0.929 & 55.2 & \\
\hline 4 & 99U031A & 66.8 & 0.063 & 0.937 & 62.6 & \\
\hline 4 & 99U032A & 59.7 & 0.075 & 0.925 & 55.2 & \\
\hline 4 & 99U037A & 62.1 & 0.037 & 0.963 & 59.8 & \\
\hline 5 & 99U045A & 54.3 & 0.022 & 0.978 & 53.1 & \\
\hline 6 & 99U054A & 64.7 & 0.150 & 0.850 & 55.0 & \\
\hline 6 & 99U056A & 55.7 & 0.037 & 0.963 & 53.6 & \\
\hline 6 & 99U058A & 53.2 & 0.060 & 0.940 & 50.0 & \\
\hline 9 & 99U108A & 50.9 & 0.026 & 0.974 & 49.6 & \\
\hline 9 & 99U110A & 76.1 & -0.072 & 0.928 & 70.6 & \\
\hline 9 & 99U111A & 77.9 & 0.126 & 0.874 & 68.1 & \\
\hline 9 & 99U112A & 65.3 & 0.039 & 0.961 & 62.8 & \\
\hline 9 & 99U114A & 73.4 & 0.082 & 0.918 & 67.4 & \\
\hline \multirow[t]{6}{*}{9} & 99U118A & 64.5 & -0.027 & 1.027 & 66.2 & \\
\hline & & & & & & s.d. \\
\hline & Mean Flow 4 & $62.9 \pm 3.6$ & & & 59.2 & 3.7 \\
\hline & Mean Flow 6 & $57.9 \pm 6.0$ & & & 52.9 & 2.6 \\
\hline & Mean Flow 9 & $68.0 \pm 10.0$ & & & 67.0 & 2.9 \\
\hline & Mean & $62.9 \pm 5.0$ & & & 59.7 & 7.1 \\
\hline
\end{tabular}

dimension.

The magnetic fabric of lava is owing to several factors, including petrofabric formed during flow. The shear produced by flow creates the orientation or alignment of minerals related to the flow conditions. For a normal magnetic fabric, mean magnetic foliation (plane perpendicular to the minimum axis $K_{\text {min }}$ ) is mostly close to the flow plane. It often exhibits a small difference in orientation (imbrication angle) relative to the flow plane (Knight and Walker, 1988). Depending on the part of the flow, it could be dipping, relative to the flow plane, upflow in the lower part of the flow or downflow in the upper part. The maximum axis $\left(K_{\max }\right)$ is mainly found (Cañon-Tapia and Pinkerton, 2000) either parallel (flow emplaced on a significant slope) or perpendicular (flow emplaced on a very weak slope) to the flow direction.

The orientation of the maximum and minimum axes of the AMS ellipsoid is presented in Fig. 10 for all sites. In Fig. 10, it is shown that $K_{\max }=K 1$ is mean on an equal area stereoplot that, together with $K_{\min }=K 3$, the mean data of Fig. 10, suggests that $K_{\min }$ and $K_{\max }$ axes are distributed on normal planes. The roughly west-east flow direction is clearly indicated by the mean magnetic foliation (plane perpendicular to the minimum axis $K_{\min }$ ) together with the parallel plane of the maximum axis $\left(K_{\max }\right)$ that suggests emplacement of the lava flows on a significant slope.

\section{Discussion and Conclusions}

The magnetic characteristics of typical samples are summarized in Figs. 6-8 and are described as follows:
(1) Characteristic remanent magnetization (ChRM) directions were isolated by means of principal-component analysis (Kirschvink, 1980), and flow mean directions were calculated from 5 to 10 samples per flow. Most of the studied samples carry a single and stable component of magnetization. Often a minor secondary component, probably of viscous origin, was present but easily removed up to $20 \mathrm{mT}$ or $250^{\circ} \mathrm{C}$. The larger part of remanent magnetization in most cases was removed at temperatures below $500^{\circ} \mathrm{C}$ which suggests that Tipoor titanomagnetite is responsible for the remanent magnetization. Site-mean inclinations vary from 30.4 to $37.8^{\circ}$, and site-mean declinations vary from 356.2 to $5.1^{\circ}$ (Table 1). The overall mean direction calculated from 10 sites is $N=10$, Dec $=1.1^{\circ}, \mathrm{Inc}=34.1^{\circ}$, $k=531$ and $\alpha_{95}=2.1^{\circ}$. Overall and site-mean directions are distributed close to the dipolar direction $\left(\operatorname{Inc}=35.3^{\circ}\right)$. The overall mean direction has very low, within-site angular dispersion of characteristic NRM (ChNRM) directions, as expected for young, fresh basalts with univectorial remanences.

(2) Variation of low-field susceptibility with high temperature showed, in some cases, the presence of a single ferrimagnetic phase with Curie point compatible with Ti-poor titanomagnetite. However, the cooling and heating curves are often not reversible (indicating transformation of maghemite to magnetite during the heating). Some samples (99U100) curves show an anomalous peak of susceptibility around $350-400^{\circ} \mathrm{C}$ on heating that may correspond to the maghemite subsequently transformed to magnetite (Özdemir, 1987). 


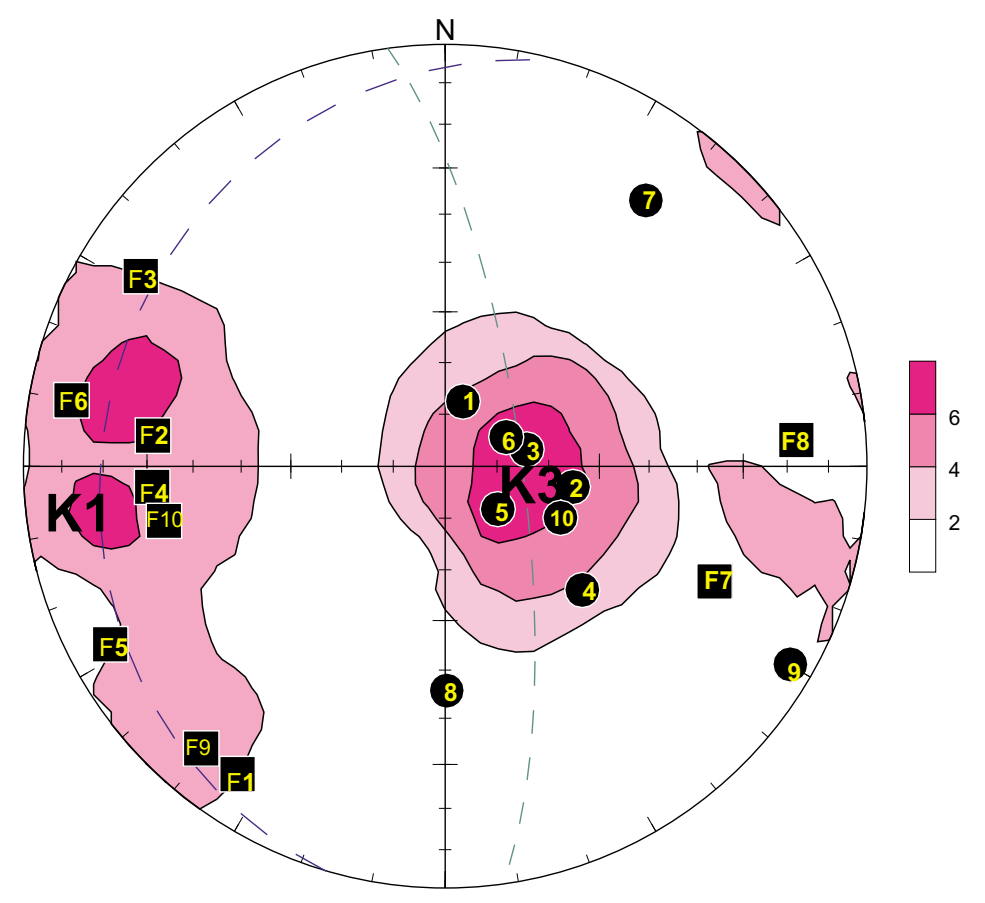

Fig. 10. Equal area projection (lower hemisphere) of the directions of the principal susceptibilities measured in the lava flows. $K_{\max }=K 1$ (squares), $K_{\min }=K 3$ (circles) mean for all 10 lava flows. Dashed line indicates the best fitting plane calculated from the principal component analysis for $K 1$ and $K 3$. Density distribution was calculated using a Starkey Fixed Circle.

Table 4. Previous paleointensity results from the Xitle volcano.

\begin{tabular}{cccl}
\hline Site & PI $(\mu \mathrm{t})$ & Samples & Reference \\
\hline JM & $59.2 \pm 11.0$ & 9 & Morales (1995) \\
XI & $60.0 \pm 9.6$ & 6 & Urrutia-Fucugauchi (1996) \\
CU & $72.6 \pm 14.2$ & 51 & Böhnel et al. (1997) \\
S9 & $76.6 \pm 23.3$ & 6 & Gonzalez et al. (1997) \\
MX & $58.3 \pm 9.5$ & 17 & Böhnel et al. (2003) \\
GT & $43.5 \pm 9.8$ & 8 & Alva (unpublished) \\
NG & $56.1 \pm 5.9$ & 8 & Nagata et al. (1965) \\
LA & $59.9 \pm 7.7$ & 56 & This study \\
Mean & $60.71 \pm 10.2$ & All data & \\
\hline
\end{tabular}

Nevertheless, both experimental and theoretical studies (Heider and Dunlop, 1987; Özdemir and Dunlop, 1989; Nishitani and Kono, 1989) show that chemical remagnetization by maghemitization has the same direction as the original TRM. Thus, paleodirections were most possibly non-affected by this alteration and they can be used for determining magnetic polarities and mean paleodirections.

(3) Hysteresis measurements at room temperature were performed on all studied sampled-sites (Fig. 7). The curves are symmetrical in all cases. Near the origin, no potbellied and wasp-waisted behavior (Tauxe et al., 1996) was detected, which probably reflect very restricted ranges of the opaque mineral coercivities. For all samples, small pseudo-single-domain grains seem to be responsible for remanence, judging from hysteresis parameters values (Day et al., 1977; Fig. 8A). This probably suggests a mixture of MD and a significant amount of SD grains. Let us note that if some superparamagnetic fraction also exists in these samples, the measured coercive force and saturation magnetization are somewhat lower and larger, respectively, than those ferrimagnetic fractions alone.

(4) The AMS study indicates that the mean maximum susceptibility parallels the geologically-inferred (westeast) flow direction in all 10 units. Deviation of the local motion from that of the unit as a whole resulted from a negligible or varying slope (Fig. 10).

(5) Earlier PI studies of the Xitle lava flow disclose intensely varying mean paleointensities (Table 4), ranging from 58 to $77 \mu \mathrm{T}$ (Böhnel et al., 1997, 2003; Gonzalez et al., 1997; Nagata et al., 1965; MoralesContreras, 1995; Morales et al., 2003; UrrutiaFucugauchi, 1996). All of these studies were performed on single or several lava flows exposed at dis- 
tinct places over the flanks of the volcano. PI results of the complete succession of 10 lava flows (this study), according to reliability parameters, are of reasonable quality. The site mean intensities range from $48.6 \pm 7.9$ to $73.9 \pm 9.9 \mu \mathrm{T}$. The mean value obtained for nine sites is $59.9 \pm 7.7 \mu \mathrm{T}$, which is consistent with the global data for this time-period. Common to all studies is that the PI was higher than the present field intensity of $43 \mu \mathrm{T}$. This is in general conformity with archeomagnetic results from the USA (Sternberg, 1989) and other data from the rest of the world (McElhinny and Senanayake, 1982), which show that paleointensities around 2000 BP were 30-40\% higher than today. The GT mean archeointensity determination (Table 4) comes from Maya pottery collected in the Kaminaljuyú area (Guatemala) that belong to an age $\sim 100$ BC (manuscript in preparation).

In summary, the characteristic magnetic directions determined in this study seem to be of primary TRM origin. This is supported by the thermomagnetic investigations which show that the remanence is carried, in most cases, by Ti-poor titanomagnetite, resulting from oxy-exsolution of original titanomagnetite during the initial flow cooling. Unblocking temperature spectra and relatively high coercivity suggest small pseudo-single domain magnetic structure grains as being responsible for remanent magnetization. The single-component linear demagnetization plots observed in the majority of cases and susceptibilitytemperature curves throughout the 10 lava flows suggests that they should be suitable for PI experiments.

Since the last decade, several studies have shown that the standard Thellier method sometimes gives incorrect PIs (e.g. Kosterov and Prèvot, 1998; Tanaka and Kono, 1991; Calvo et al., 2002; Biggin and Thomas, 2003; Yamamoto et al., 2003; Kissel and Laj, 2004; Mochizuki et al., 2004; Chauvin et al., 2005; Pan et al., 2005). Possible causes for this could be local magnetic anomalies, multidomain effects, irreversible physical changes in PSD grains, and thermal alteration due to laboratory heating.

In order to decipher the most plausible source and to find the solution to this problem, research has reached diverse conclusions and/or suggestions as follows: (1) Biggin and Thomas (2003) conclude that pTRM checks, and other criteria, can be passed by samples that yield significantly erroneous PI estimates and can be failed by samples that record the paleofield faithfully, so, the need for further intensive PI studies is clear; (2) Biggin et al. (2003) found that there is no geomagnetic reason for the anomalously high dispersion of the PI data sets. They suggest non-ideal factors influencing the individual results, and amongst these possible factors/findings are (a) variation of the cooling rate through the flow. This can directly affect the intensity of the TRM (and so the PI estimate) in different parts of the flow (Fox and Aitkin, 1980). Also, cooling history is significant in defining the magneto-mineralogy and domain state of the rock which PI estimation can be extremely sensitive to. (b) A small measured dispersion for a small number of samples is no guarantee that the mean is representative of that for the flow as a whole. (c) Suggest sampling maximiz-

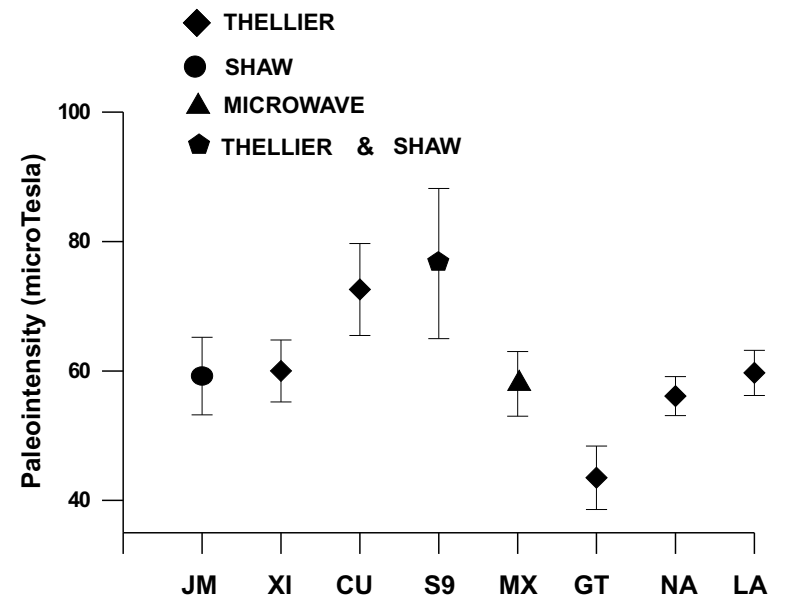

Fig. 11. Previous paleointensity determinations of the Xitle lavas.

ing the vertical coverage of the lava flow. (3) Curved or S shaped Arai plots from PI experiments were studied by Coe et al. (2004). They found that using the slope of only the lower or higher temperature NRM-TRM points would lead to estimates that are 30-80\% too high or too low. Excellent agreement with the known regional field intensity is found when the slopes of lines connecting the end points of the PI experiments are used. They suggest that the curvature of the NRM-TRM plot arises from the MD-like behavior of magnetic grains that exhibited PSD- to MD-like properties rather than from oxyexsolution or some other physicochemical alteration during laboratory heating. (4) Chauvin et al. (2005) conclude that the best fitting line through all points with successful pTRM checks and no CRM acquisition leads to more accurate PI results than trying to define the "straightest" line. To explain the overestimated PI, they consider two physical processes that arise from the much slower initial cooling of the rock in nature than heating/cooling cycles in the laboratory during Thellier experiments. Cooling-rate-dependence of TRM and high temperature VRM, augment the initial primary NRM arising from the slower initial cooling of the rock in nature versus the more rapid heating/cooling cycles during the laboratory experiments. This enhanced NRM can lead to an overestimation of PI determinations when only lower temperature data are considered. Also, PI overestimation can result for PSDMD particles, caused by the asymmetry of TRM acquisition and demagnetization, when only lower temperature data are considered.

The overall mean PI result, higher than the present field intensity, could be due to heating steps that alter the magnetic mineralogy, or to the criteria for selection of reliable PI determinations based mainly on the examination of the Arai plots.

Previous PI results of Xitle lava flows (Böhnel et al., 1997, 2003; Gonzalez et al., 1997; Nagata et al., 1965; Morales-Contreras, 1995; Morales et al., 2003; and UrrutiaFucugauchi, 1996) found very similar mean values to our mean PI estimate (Fig. 11, Table 4). Combining all of the previous data results in $60.7 \pm 10.2 \mu \mathrm{T}(N=8)$. This value is slightly higher than our mean value. Therefore, the appar- 
ent agreement of the mean values from all the previous studies, and this study, always higher than the present-day field, cannot be explained by experimental errors alone. At this point, it should be mentioned that the Xitle flow probably cooled down within a time span much shorter than the typical periods of geomagnetic intensity variations. The cooling time of 150 days proposed by Böhnel et al. (1997) suggests that a geomagnetic origin for the observed PI variations is excluded. This is supported by the directional data, which are uniform throughout the flow.

In his comprehensive review of time variation in geomagnetic intensity, Valet (2003) indicates a permanent search for improving data quality and, hence, reliability. However, the reliability of determinations of absolute PI has not improved significantly but much care has been taken to include additional checks and criteria before accepting a field determination.

However, similar conclusions are reached by different workers using distinct methodology, and following the suggestion of Biggin et al. (2003) and Chauvin et al. (2005), in order to look for an explanation of the abnormally high dispersion of PI estimates, I tested the cooling rate dependence of TRM, investigated following a modified procedure suggested by Chauvin et al. (2000).

Unfortunately, most of the samples presented values of $R_{13}$ greater than $15 \%$, and no cooling rate correction was made to these samples. Those samples on which coolingrate correction was applied give a flow mean of $59.7 \pm 7.1$ lower than the raw PI data (Table 3), as was expected, but very similar to the mean value obtained for the nine sites $59.9 \pm 7.7 \mu \mathrm{T}$. Currently, we are investigating the possible causes of intra-flow variation of PI on a detailed vertical sampling of lava flow number 6 of this work. The effect of cooling rate upon acquisition of TRM in volcanic rocks also seems to be critical, as in archeomagnetic investigations.

Acknowledgments. I appreciate the useful comments and discussions of Dr. H. Böhnel and an anonymous reviewer that improved the scientific content and structure of this work. I also thank my colleagues A. Goguitchaichvili, J. Morales and C. Caballero for their suggestions and comments. Assistance in the field-laboratory and mineralogy studies was provided by R. Galvan, A. Gonzalez and M. Rivas. I thank G. Aguilar-Palma from the Laboratorio de Analisis Integral de Muestras de Roca, Instituto Mexicano del Petroleo, for his help in the preparation of the polished sections. I also acknowledge the financial support of CONACyT $42682 \mathrm{~F}$ research project.

\section{References}

Arnold, J. T. and W. F. Libby, Radiocarbon dates, Science, 113, 111-120, 1951.

Badilla-Cruz, R. R., Estudio petrológico de la lava de la parte noreste del Pedregal de San Angel, D.F., Bol. Soc. Geol. Mex., 38, 40-57, 1977.

Baer, E. M., R. V. Fisher, M. Fuller, and G. Valentine, Turbulent transport and deposition of the Ito pyroclastic flow: determinations using anisotropy of magnetic susceptibility, J. Geophys. Res., 102, 22,56522,586, 1997.

Biggin, A. J. and D. N. Thomas, The application of acceptance criteria to results of Thellier palaeointensity experiments performed on samples with pseudo-single-domain-like characteristics, Phys. Earth Planet. Inter., 138, 279-287, 2003.

Biggin, A. J., H. N. Böhnel, and F. R. Zuñiga, How many palaeointensity determinations are required from a single lava flow to constitute a reliable average?, Geophys. Res. Lett., 30(11), 1575, doi:10,1029/2003GL017146, 2003.
Böhnel, H., J. Morales, C. Caballero, L. Alva-Valdivia, G. McIntosh, S Gonzalez, and G. Sherwood, Variation of rock magnetic parameters and paleointensities over a single holocene lava flow, J. Geomag. Geoelectr., 49, 523-542, 1997.

Böhnel, H., A. J. Biggin, D. Walton, J. Shaw, and J. A. Share, Microwave palaeointensities from a recent Mexican lava flow, baked sediments and reheated pottery, Earth Planet. Sci. Lett., 6751, 1-16, 2003.

Buddington, A. F. and D. H. Lindsley, Iron-titanium oxide minerals and synthetic equivalents, J. Petrol., 5, 310-357, 1964.

Bullard, F. M., Volcanoes of the Earth, University of Queensland Press, Saint Lucia, 1976.

Calvo, M., M. Orévot, M. Perrin, and J. Riisager, Investigating the reasons for the failure of paleointensity experiments: a study on historical lava flows from Mt Etna (Italy), Geophys. J. Int., 149, 44-63, 2002.

Cañon-Tapia, E. and H. Pinkerton, The anisotropy of magnetic susceptibility of lava flows: an experimental approach, J. Volcanol. Geotherm. Res., 98, 219-233, 2000.

Chauvin, A., Y. Garcia, Ph. Lanos, and F. Laubenheimer, Paleointensity of the geomagnetic field recovered on archaeomagnetic sites from France, Phys. Earth Planet. Int., 120, 111-136, 2000.

Chauvin, A., P. Roperch, and S. Levi, Reliability of geomagnetic paleointensity data: the effects of the NRM fraction and concave-up behavior on paleointensity determinations by the Thellier method, Phys. Earth Planet. Inter., 150, 265-286, 2005.

Coe, R. S., S. C. Grommé, and E. A. Mankinen, Geomagnetic paleointensities from radiocarbon-dated lava flows on Hawaii and the question of the Pacific non-dipole low, J. Geophys. Res., 83, 1740-1756, 1978.

Coe, R. S., J. Riisager, G. Plenier, R. Leonhardt, and D. Krása, Multidomain behavior during Thellier palaeointensity experiments: results from the 1915 Mt. Lassen flow, Phys. Earth Planet. Inter., 147, 141-153, 2004.

Day, R., M. Fuller, and V. A. Schmidt, Hysteresis properties of titanomagnetites: Grain-size and compositional dependence, Phys. Earth Planet. Inter., 13, 260-267, 1997.

Delgado, H., R. Molinero, P. Cervantes, J. Nieto-Obregón, R. LozanoSanta Cruz, H. L. Macias-González, C. Mendoza-Rosales, and G. SilvaRomo, Geology of the Xitle volcano in southern Mexico City-A 2000year-old monogenetic volcano in an urban area, Rev. Mex. Ciencias Geol., 15(2), 115-131, 1998.

Fox, J. M. W. and M. J. Aitkin, Cooling-rate dependence of thermoremanent magnetization, Nature, 283, 462-463, 1980.

Gonzalez, S., G. Sherwood, H. Böhnel, and E. Schnepp, Palaeosecular variation in central Mexico over the last 30,000 years, Geophys. J. Int., 130, 201-219, 1997.

Gonzalez, S., A. Pastrana, C. Siebe, and G. Duller, Timing of the prehistoric eruption of Xitle Volcano and the abandonment of Cuicuilco Pyramid, Southern Basin of Mexico, in: The Archaeology of Geological Catastrophies, Geol. Soc. London, Sp. Pub., 171, 205-224, 2000.

Grommé, C. S., T. L. Wright, and D. L. Peck, Magnetic properties and oxidation of iron-titanium oxide minerals in Alae and Makaopuhi lava lakes, Hawaii, J. Geophys. Res., 74, 5277-5293, 1969.

Haggerty, S. E., Oxidation of opaque mineral oxides in basalts, in Oxide Minerals, edited by D. Rumble, Mineral. Soc. Am., Short Course Notes, Hg1-Hg100pp, 1976.

Heider, F. and D. J. Dunlop, Two types of chemical remanent magnetization during oxidation of magnetite, Phys. Earth Planet. Inter., 46, 24-45, 1987.

Herrero-Bervera, E., J. Urrutia-Fucugauchi, A. L. Martin del Pozzo, H. Bohnel, and J. Guerrero, Normal amplitude Brunhes paleosecular variation at low-latitudes: a paleomagnetic record from the Trans-Mexican Volcanic Belt., Geophys. Res. Lett., 13, 1442-1445, 1986.

Kirschvink, J. L., The least-square line and plane and analysis of palaeomagnetic data, Geophys. J. R. Astron. Soc., 62, 699-718, 1980.

Kissel, C. and C. Laj, Improvements in procedure and paleointensity selection criteria (PICRIT-03) for Thellier and Thellier determinations: application to Hawaiian basaltic longcores, Phys. Earth Planet. Int., 147, 155-159, 2004.

Knight, M. D. and G. P. L. Walker, Magma flow directions in dikes of the Koolau complex, Oahu, determined from magnetic fabric studies, $J$. Geophys. Res., 93, 4301-4319, 1988.

Kosterov, A. and M. Prévot, Possible mechanisms causing failure of the Thellier palaeointensity experiments in some basalts, Geophys. J. Int., 134, 554-572, 1998.

Luhr, J. F. and T. Simkin, (Eds), Paricutin. The volcano born in a Mexican cornfield, Geoscience Press, Inc., Arizona, USA, 427 pp., 1993. 
McElhinny, M. W. and W. E. Senanayake, Variations in the geomagnetic dipole 1: the past 50,000 years, J. Geomag. Geoelectr., 34, 39-51, 1982.

Mochizuki, N., H. Tsunakawa, Y. Oishi, S. Wakai, K. Wakabayashi, and Y. Yamamoto, Palaeointensity study of the Oshima 1986 lava in Japan: implications for the reliability of the Thellier and LTD-DHT Shaw methods, Phys. Earth Planet. Inter., 146, 395-416, 2004.

Morales-Contreras, J. J., Determinación de paleointensidades del campo geomagnetico para el Cuaternario en la Sierra Chichinautzin, Ms.Sc. Thesis, UNAM, Mexico, 1995.

Morales, J., A. Goguitchaishvili, L. M. Alva-Valdivia, and J. UrrutiaFucugauchi, An attempt to determine the microwave paleointensity on Paricutin volcano lava flows (Central Mexico), Geofis. Inter., 42(1), 95100, 2003.

Nagata, T., R. M. Fisher, and K. Momose, Secular variation of the geomagnetic total force during the last 5000 years, J. Geophys. Res., 68 , 5277-5281, 1963.

Nagata, T., K. Kobayashi, and E. J. Swarz, Archeomagnetic intensity studies of South and Central America, J. Geomag. Geoelectr., 17, 399-405, 1965.

Nishitani, T. and M. Kono, Effects of low-temperature oxidation on the remanence properties of titanomagnetites, J. Geomag. Geoelectr., 41, 19-38, 1989.

O'Reilly, W., Rock and Mineral Magnetism, 220 pp., Blackie \& Son, 1984

Özdemir, O., Inversion of titanomaghemites, Phys. Earth Planet. Int., 65 , 125-136, 1987.

Özdemir, O. and D. J. Dunlop, Chemico-viscous remanent magnetization in $\mathrm{Fe}_{3} \mathrm{O}_{4}-\gamma \mathrm{Fe}_{2} \mathrm{O}_{3}$ system, Science, 243, 1043-1047, 1989.

Palmer, H. C. and W. D. MacDonald, Anisotropy of magnetic susceptibility in relation to source vents of ignimbrites: empirical observations, Tectonophys., 307, 207-218, 1999.

Pan, Y., M. Hill, and R. Zhu, Paleomagnetic and paleointensity study of an Oligocene-Miocene lava sequence from the Hannouba basalts in northern China, Phys. Earth Planet. Inter., 151, 21-35, 2005.

Siebe, C., Age and archaeological implications of Xitle volcano, southwestern Basin of Mexico-City, J. Volcanol. Geoth. Res., 104, 45-64, 2000 .
Sternberg, R. S., Archaeomagnetic palaeointensity in the American southwest during the last 2000 years, Phys. Earth Planet. Int., 56, 1-17, 1989.

Tanaka, H. and M. Kono, Preliminary results and reliability of palaeointensities studies on historical and ${ }^{14} \mathrm{C}$ dated Hawaiian lavas, J. Geomag. Geoelectr., 43, 375-388, 1991.

Tauxe, L., T. A. T. Mullender, and T. Pick, Pot-bellies, wasp-waists and superparamagnetism in magnetic hysteresis, J. Geophys. Res., 95, 12337 12350, 1996.

Tauxe, L., H. N. Bertram, and C. Seberino, Physical interpretation of Hysteresis loops: micromagnetic modeling of fine particle magnetite, Geochem. Geophys. Geosys., 3, 1-22, 2002.

Thellier, E. and O. Thellier, Sur l'intensité du champ magnétique terrestre dans le passé historique et géologique, Ann. Géophysique, 15, 285-376. 1959.

Urrutia-Fucugauchi, J., Paleomagnetic study of the Xitle-Pedregal de San Angel lava flow, southern basin of Mexico, Phys. Earth Planet. Int., 97, 177-196, 1996

Urrutia-Fucugauchi, J. and A. L. Martin del Pozzo, Implicaciones de los datos paleomagnéticos sobre la edad de la Sierra de Chichinautzin, Cuenca de México, Geof. Int., 32, 523-533, 1993.

Valet, J.-P., Time variations in geomagnetic intensity, Rev. Geophys., 41(1), 1004, doi:101029/2001RG000104, 2003.

Walker, G. P. L., Origin of vesicle types and distribution patterns in the Xitle pahoehoe basalt in Mexico City, Am. Geophys. Un., Min. Soc. Am., Fall Meeting, Baltimore, Programme with Abstracts, p. 566, 1991.

Williams, W. and D. J. Dunlop, Simulation of magnetic Hysteresis in pseudo-single-domain grains of magnetite, J. Geophys. Res., 100, 38593871, 1995.

Yamamoto, Y., H. Tsunakawa, and H. Shibuya, Palaeointensity study of the Hawaiian 1960 lava: implications for possible causes of causes of erroneously high intensities, Geophys. J. Int., 153, 263-276, 2003.

L. M. Alva-Valdivia (e-mail: lalva@geofisica.unam.mx) 